\title{
LAS PEREGRINACIONES EN LA ANTIGÜEDAD
}

\author{
LUIS GARCÍA IGLESIAS
}

Cuando la gran peregrinación de un hombre bueno

Como han señalado los teóricos del fenómeno, la peregrinación se caracteriza por estos tres rasgos esenciales: un lugar sagrado, desplazamiento de individuos o grupos hacia él y esperanza de alcanzar un bien concreto, sea en la dimensión material, sea en la espiritual (1). Es decir; se trata de un viaje individual o colectivo, con motivaciones religiosas, hacia un lugar sagrado. La peregrinación es algo consubstancial a la religiosidad localizada, a la religiosidad de santuario. La referencia a un lugar religiosamente significativo, la atracción por él y hacia él; la generalización de una creencia, de una sensación, de una necesidad de efectos compensativos, consoladores y hasta taumatúrgicos, llevan a la movilización constante de masas a dicho lugar sagrado, lo que comporta luego consecuencias de índole social que exceden al propio hecho religioso en sí. Porque, al margen de las motivaciones profundas que puedan mover al peregrino en determinada referencia geográfica, ¿qué es éste? Un viajero. ¿Qué conlleva el viaje masivo? Contacto entre gentes diferentes, entre realidades culturales distintas. ¿Qué efectos arrastra la atracción unidireccional? Cosmopolitismo en la región receptora del elemento foráneo. ¿Qué exige esta masa que afluye? Atenciones, servicios, infraestructura. ¿Y qué trae? Dinero, poco o mucho cada viajero, pero en cantidades fabulosas la colectividad que se mueve; trae riqueza, trae invitación a la iniciativa, trae activación de recursos. Y lo que comienza por ser algo sentido por cada cual iriternamente en pura y simple dimensión religiosa, viene a ser con el tiempo y desde fuera, en cuanto que fenómeno general, una complicada realidad social, económica y cultural de un alcance infinitamente mayor, en muy varias dimensiones, de esa vivencia religiosa que es fundamento último del trasiego constante a un cierto lugar sagrado.

Por lo general, los santuarios receptores de piadosos visitantes están ligados a los centros de origen y entre sí por itinerarios salpicados de lugares santos menores y secundarios, y por hospederías, mesones y paradas, que suponen para el viajero respectivamente recordatorios y estímulos para su inquietud religiosa y servicios

(1) Raphaël, F.: "Le pèrelinage. Approche sociologique", Les pélerinages de l'antiquité biblique et classique à l'Occident médiéval, París, 1973, pág. 11. 
en sus necesidades materiales, incluso vigilancia y garantía de la seguridad del peregrino en pasos difíciles. Es una constante del fenómeno peregrino la despreocupación por el camino más corto en beneficio de un circuito religiosamente significativo y simbólica, vivencial y sobrenaturalmente denso. Esta ruta típica e institucionalizada tiene mucho de ruta turística en el sentido de que brinda servicios y ofrece al viajero cuanto su cuerpo y su espíritu demandan y, por lo tanto, cuanto humanamente precisa y espiritualmente puede colmarle. Hay otra constante en la religiosidad de santuario foco de atracción peregrina: el uso de exvotos - esa mano, esos senos, esos ojos, esa pierna-, generalmente ahora de cera, y en la antigüedad de cera, de metal y muy frecuentemente de barro; en estos objetos queda materialmente expresado el agradecimiento del fiel por la merced que considera recibida. Y en el plano más inmediato constituyen una industria, un comercio, un servicio, un negocio al socaire y al pretexto del hecho religioso. Y lo mismo cabe decir de las víctimas para el sacrificio, si de un santuario sacrificial se trata. Por lo dicho, por lo de más allá, porque hay que comer, porque hay que dormir, porque la picaresca asalta, porque hasta el propio santuario tiene algo o mucho de zoco, el viajero peregrino va exprimiendo su más o menos generoso bolsillo desde que sale hasta que llega y luego también en el regreso. Y junto a esta dimensión económica, no se olvide la función política, quizá no intencionada, quizá sí, como puede ser la peregrinación en cuanto que factor de unificación entre pueblos diversos, sometidos por lo demás a una dinámica de disgregación y, a la larga, cohesionados de alguna suerte por este fenómeno religioso. Todo esto hace de la peregrinación un fenómeno fascinante, con una sociología permanente, válida no sólo para las manifestaciones del mundo moderno y de la Edad Media, cuanto para las de la Antigüedad, que son las que ahora interesan aquí.

Se puede decir que en la medida en que existe una religiosidad de santuario se da, en potencia al menos, el fenómeno del peregrinaje. Si no va el objeto del santuario al creyente, tendrá necesariamente éste que acudir al santuario. Y como el desplazamiento del objeto religioso no es posible en muchos casos - por ejemplo, la presencia de Dios de Israel en el Templo de Jerusalén llegará un momento en que no se pueda desplazar-, el peregrinaje es la recíproca necesaria. Y es que el creyente precisa de una cercanía física a la realidad religiosa de su referencia.

Hace pocos años, en 1974-1975, se descubrió en un yacimiento arqueológico sirio un impresionante conjunto de tablillas inscritas, millares y millares, todo un archivo, que, debidamente estudiadas y mediante diversos trabajos especializados de los que es particularmente destacable una monografía de 1979 (2), han puesto en conocimiento del mundo científico y del hombre culto en general, interesado por la historia, lo que fue el más antiguo imperio semítico del Próximo Oriente; una realidad política, social y culturalmente insospechada hasta que se fueron haciendo públicos los primeros hallazgos significativos. Se trata del imperio que tenía como centro o capital la ciudad de Ebla. Los documentos son del III milenio a. C. Hay, efectivamente, en el archivo textos de contenido religioso: dioses,

(2) Pettinato, G.: Ebla, un impero inciso nell'argilla, Milán, 1979. 
santuarios, clero, manifestaciones de culto, ofrendas... (3). La impresión que se recibe leyendo estos textos es que lo religioso estaba profundamente integrado en la cotidianeidad de las gentes que habitaban tan dilatado imperio y que los templos eran lugares de gran actividad sacrificial. No puede extrañar que una religiosidad tan vivamente sentida exija la cercanía del hombre al dios en algunas ocasiones, cosa no fácil, habiendo distancias al medio. Tenemos documentadas en el archivo procesiones de las divinidades de la capital a otros puntos geográficos del reino (4). El centro y la periferia, el dios y los creyentes unidos mediante este peregrinar inverso; el dios es quien peregrina. Obviamente, debía de tratarse de un acontecimiento extraordinario y no del todo frecuente. Y también obviamente debía de darse la peregrinación normal, la del creyente al santuario, si bien este fenómeno menos aparatoso por más trivial y más particular, no merecía los honores de quedar registrado en el archivo de palacio. Ahí está el hecho: la religión de santuario, que teóricamente separa al dios u objeto religioso del creyente distante, arbitra una solución aproximativa mediante el movimiento del objeto religioso hacia el creyente o el del creyente hacia el objeto religioso, siendo esto último el peregrinaje.

La religión egipcia aporta dos elementos particularmente influyentes de cara a la atracción de fieles a los santuarios: me refiero al iniciático y al oracular. La religiosidad de iniciación comporta un rito significado de vinculación a un dios en un momento determinado de la vida del individuo, o tras una opción voluntaria y vocacional; y ese rito se realiza fundamentalmente en templos específicos que acogen ese mundo religioso de misterio. La religiosidad de oráculo no es otra cosa que la de aquellos santuarios donde se consulta a un dios, quien, pretendidamente de forma directa, o a través de un sacerdote o una pitonisa (tomemos el nombre del uso griego generalizado), responde para gobierno e incluso salvación del consultante.

Tanto los altos lugares de iniciación como los altos lugares de consulta oracular movilizan en el antiguo Egipto masas de peregrinos. Abidos es la ciudad santa por excelencia para los antiguos egipcios y punto de atracción principal para iniciados y futuros iniciados en sus misterios. Hasta lo era para quienes veían acercarse su última y definitiva peregrinación. Allí, Osiris, el salvador, esperaba a sus fieles para conducirles al más allá (5). Y si Osiris tenía en Abidos su tumba, su cuna la tenía en Busiris, que era otro centro importante de iniciación y de atracción de viajeros; en el centro del delta, contrariamente a Abidos, que se encontraba muy Nilo arriba, cerca de Tebas. Los restos arqueológicos de Busiris son ricos, aunque escasos; es gracias a la documentación egipcia escrita a lo que debemos la seguridad de que el de Busiris era el primero de los templos de Osiris en antigüedad y en peregrinaje (6). También Heródoto, autor griego del siglo V a. C., testimonia la grandeza del complejo sagrado de Busiris y la nutrida afluencia de fieles, así como las instalaciones y servicios existentes en función de los muy numerosos viajeros. Todo ello en vigencia cuando escribía el historiador de Halicarnaso. Otros importantes focos de

(3) Pettinato: Ebla..., págs. 265 y ss.

(4) Pettinato: Ebla..., págs. 276-277.

(5) Guilmot, M.: Les initiés et les rites initiatiques en Egypte ancienne, París, 1977, págs. 91 y ss.

(6) Guilmot: Les initiés..., págs. 136 y ss. 
atracción de peregrinos eran Karnak y Luxor, sobre todo el primero de estos dos lugares. En ambos centros se conservan impresionantes vestigios artísticoarqueológicos, especialmente templos. Karnak no sólo era uno más de los lugares de iniciación de los creyentes en Osiris, sino que era a un tiempo la ciudad de Amón$\mathrm{Re}$, el poderoso dios del Egipto del sur, o alto Egipto. Como señala Guilmot, dos mil años de pillaje no han llegado a destruir del todo este colosal conjunto arquitectónico, en el que sobresalen especialmente los santuarios y en el que se acumuló riqueza artística sin par durante otros dos mil años (7).

En cuanto a la peregrinación a lugares santos de religiosidad oracular, la manifestación más interesante es la del oráculo de Amón en Siwa, que atraía a muchos creyentes del dios y que fue objeto de rendida visita por parte de Alejandro Magno, cuando el joven rey macedonio conquistó Egipto en el paseo triunfal que hizo dar a sus ejércitos por todo el Próximo Oriente (8). Los griegos -Alejandro era un macedonio helenizado - tenían, como veremos, su larga tradición peregrina. Pero antes de pasar a ella debo decir algo de la peregrinación en la religiosidad de Israel, un hito importante en la historia del fenómeno de acercamiento a los santuarios, porque el peregrinaje, aunque conocido por otros pueblos y en religiosidades varias, es un fenómeno de civilización típicamente ligado a los mundos judaico, cristiano e islámico.

Son muchos los lugares santos de la época bíblica relacionados con hitos de la vida de los patriarcas o puras y simples asunciones de los viejos santuarios paganos cananeos por parte de los creyentes de Israel (9). Algunos de estos lugares santos tienden a sobrepasar el mero interés local para convertirse en centro religioso de más de una tribu. Es el caso de Siquém, por ejemplo, que aglutina las tribus del norte; es el caso de Guilgal para las del sur. Sobre todo es el caso de Siló, que acoge el arca de la alianza hasta la conquista filistea y da lugar a un peregrinaje verdadero, el primero propiamente dicho de que los téxtos bíblicos nos dan información (10). El comienzo del I libro de Samuel nos informa sobre peregrinos y sacerdotes, los últimos aprovechándose de los primeros (11). El papel de Siló en la religiosidad israelita del último período de los Jueces y comienzos de la monarquía es fundamental; aunque luego, a raíz de la destrucción del santuario por los filisteos, será Jerusalén la ciudad que continúe explícitamente la tradición; Jerusalén, la nueva capital de todo Israel desde los tiempos de David; la vieja ciudad jesubea de cuyo templo a El, el dios semítico por excelencia, hará Yahvé su principal morada desde

(7) Guilmot: Les initiés..., págs. 161 y ss.

(8) Tarn, W. W.: Alexander the Great, reimpr. Cambridge, 1979, I, págs. $42-44$ y II, págs. 347 y ss., y Hammond, N. G. L.: Alexander the Great, King, Commander and Statesman, Londres, 1981, págs. 125-126 y 266 y ss. En general, sobre los oráculos en Egipto. Morenz, S.: Egyptian Religion, Londres, 1973, págs. 101 y ss.

(9) Chélini-H. Branthomme, J.: Les chemins de Dieu. Histoire des pélerinages chretien des origins à nos jours, París, 1982, págs. 27-29. Sobre los lugares de culto de la antigüedad bíblica, véase el conjunto de trabajos recogidos en Temples and High Places in Biblical Times, Jerusalén, 1981.

(10) Sobre este santuario, su historia y su arqueología, véase Kempinski, A.: "Shiloh", en Avi-Yonah M.-Stern, E. (edd.): Encyclopedia of Archaeological Excavations in the Holy Land, IV, Oxford-Jerusalén, 1978, págs. 1.098 y ss.

(11) I Samuel, I, 3-28 y II, 13-17. 
el reinado de Salomón (12). El templo de Jerusalén, sobre todo en eṕoca postbíblica, pero realmente desde las reformas de Ezequías, será el centro de atracción de los israelitas, y no sólo por peregrinaciones espontáneas, sino también por las de carácter ritual, obligatorias, impuestas para algunas situaciones de la vida de las personas y para algunas fiestas (13). Quedan dispensados de la peregrinación los niños por debajo de los doce años, las mujeres, los viejos, los enfermos, los ciegos y los esclavos (14). Los peregrinos afluían no solamente desde Judea, sino desde toda Palestina, desde todo el Próximo Oriente, desde toda la diáspora mediterránea. Largas caravanas que exigían unas atenciones en camino y que, sobre todo, precisaban en Jerusalén de una organización asistencial suficiente, unos servicios y una mecánica que hiciera posible el orden en lo referente a los sacrificios. Los famosos mercaderes del templo son un elemento de esta cadena infraestructural que ofrecía Jerusalén a los piadosos viajeros que a ella llegaban para cumplir con el compromiso del peregrinaje obligatorio. Flavio Josefo, un historiador judío del siglo I d. C., habla de unos tres millones de peregrinos en Jerusalén durante la Pascua de cada año. La cifra está sin duda muy abultada, pero de todas maneras la afluencia era masiva (15). El período de las peregrinaciones comenzaba con la suavización del rigor del invierno y terminaba con la llegada del otoño; de marzo a septiembre, digamos. Los viajeros se preparaban, se formaban los grupos que viajarían en caravana por malos caminos hasta que los romanos se hicieron cargo de ellos, se establecían los servicios de vigilancia oportunos, preparaban los comerciantes sus mercancías y se aprestaban los bandoleros, codiciosos del dinero que siempre porta un viajero y del tributo o segundo diezmo que estos fieles peregrinos llevaban a Jerusalén. Había albergues en toda población de cierta entidad y especialmente en la propia ciudad santa. Una curiosa inscripción encontrada en la colina jerosolimitana de Ofel, continuación hacia el sur de la plataforma del Templo, nos informa de que se había dispuesto en una sinagoga allí fundada habitaciones y cisternas para dar cobijo y posada a los extranjeros necesitados de ello (16). Eran sin duda muchas las hospederías de este tipo, complementarias, porque en los días de fiesta era difícil encontrar mejor alojamiento. En dichas ocasiones se llenaban las localidades vecinas, por ejemplo Betania, e incluso se llegaba a habilitar las dependencias del Templo; no así el Templo propio y su explanada, área de marcadas restricciones legales y rituales (17). Ello a pesar de que el cumplimiento del deber peregrino no podía ser muy estricto (18).

A Jesuralén llegaban judíos y galileos, israelitas procedentes de Cirene y de Alejandría, ciudades griegas del norte de Africa, de Cilicia y otras regiones de Asia,

(12) Véase Parrot, A.: El templo de Jerusalén, Barcelona, 1962.

(13) Haran, M.: Temples, Temple Service in Ancient Israel, Oxford, 1978, págs. 290 y ss.

(14) Jeremías, J.: Jerusalén en tiempos de Jesús, Madrid, 1977, pág. 93.

(15) Jeremías: Jerusalén..., pág. 95.

(16) Jeremías: Jerusalén..., págs. 75-76. Sobre la inscripción, Safrai-M, M.: Stern, The Jewish People in the First Century, Assen-Amsterdam, 1974-1976, I, págs. 192-193, y II, págs. 909-910.

(17) Jeremías, Jerusalén..., págs. 77-78. Para la dimensión económica de todo esto, véase Avi-Yonah M. Bagatti. B.-Kenyon, K. M. y otros, Todo sobre la Jerusalén bíblica, Barcelona-México, 1973, págs. 130 y ss.

(18) Haran: Temples and Temple Service..., p. 294. 
de Grecia propia, de Roma, de Chipre, de la Galia y de Germania, de Siria, Arabia, Mesopotamia y regiones situadas aún más al este; de Egipto y de Etiopía. De cualquier lugar en que hubiera comunidades judías (19). Porque todo israelita varón y todo prosélito de pleno derecho en edad y condiciones de emprender viaje estaban obligados a participar en las peregrinaciones anuales coincidentes con las tres fiestas peregrinas: Pascua, Semanas y Tabernáculos, si bien los extranjeros, sin llegar a gozar de exención, encontraban ciertas concesiones a su favor. Aún así eran muchos los llegados de lejos que, junto con los propios judíos palestinos, subían al Templo con su víctima para cumplir con el deber de sacrificio. Y gran parte de Jesuralén vivía de este trasiego.

También la antigua Grecia conoció la práctica piadosa de la peregrinación a santuarios (20). Santuarios oraculares, santuarios de misterio, santuarios terapéuticos y fiestas religiosas panhelénicas, típicas de algunos lugares. Viejos precedentes de los santuarios eran las antiguas cuevas cultuales y lugares sagrados, de larga tradición, conocidos en el ámbito egeo desde época pre- y protohistórica, especialmente en Creta, e indicativos de una religiosidad que ha superado ya el nivel de lo individual y que conoce las ofrendas votivas (21). El más famoso de los santuarios oraculares de época histórica era el de Delfos, donde la Pitia desgranaba a los consultantes los oráculos de Apolo. El principal de los santuarios terapéuticos era el de Asclepio, el dios médico, en Epidauro (22). Y las fiestas eran muchas: las Panateneas y las Dionisiacas en Atenas (23), las Istmicas en Corinto, las Olímpicas en la ciudad que les da nombre, estas últimas caracterizadas por los juegos atléticos, que suponían la parte más externa del aparato festivo. Dichas celebraciones y otras semejantes atraían a muchos viajeros (24). Delos y Eleusis, un famoso templo de Apolo y unos misterios no menos famosos respectivamente, tenían también gran poder de convocatoria; en el caso de Eleusis, con frecuencia gentes de baja estofa y mal vivir (25). Estos santuarios y estas fiestas participaban de gran carga política, de unión de todos los griegos, un aglutinante por encima del particularismo político, pues no debe perderse de vista que cada ciudad griega era políticamente independiente. Eran necesarios estos lazos de ocasión religiosa para mantener una conciencia griega unitaria, y no se conseguía nunca tal conciencia sin fisuras.

(19) Jeremías: Jerusalén..., págs. 80 y ss.

(20) En general, respecto al fenómeno, Siebert, G.: "Réflexions sur la notion de pèlerinage dans la Grèce antique»: Les pèlerinages de l'antiquité biblique et classique à l'Occident médiéval, París, 1973, págs. 33 y ss.

(21) Véase Branigan, K.: The Foundations of palatial Crete. A Survey of Crete in the Early Bronze, Age, Londres, 1970, págs. 102 y ss.; García López, J.: Sacrificio y sacerdocio en las religiones micénica y homérica, Madrid, 1970, págs. 15-16; Faure, P.: La vie quotidienne en Crète au temps de Minos (1500 a C.), París, 1973, págs. 297 y ss.; D'A. Desborough, V. R.: The Greek Dark Age, Londres, 1972, págs. 278 y ss. y Coldstream, J. N.: Geometric Greece, Londres, 1977, págs. 317 y ss.

(22) Gil, L.: Therapeia. La medicina popular en el mundo clásico, Madrid, 1969, págs. 361 y ss. y 381 y ss. y Phillips, E. D.: Greek Medicine, Londres, 1973, págs. 197 y ss.

(23) Parke, H. W.: Festivals of the Athenians, Londres, 1977, págs. 33 y ss. y 123 y ss. respectivamente.

(24) Marasco, G.: I viaggi nella Grecia antica, Roma, 1978, págs. 104 y ss.

(25) Salles, C.: Les bas-fonds de l'Antiquité. París, 1982, págs. 59-60. En general, sobre los misterios eleusinos, Mylonas, G. E.: Eleusis and the Eleusinian Mysteries, Princeton, 1961. 
Pero, sobre todo, hay que tener en cuenta el factor económico. Ya los mismos griegos antiguos eran sabedores de la importancia económica de estos viajes de última razón religiosa. Plutarco, conocido escritor griego de época romana, destaca la importancia determinante del oráculo de Apolo para la prosperidad de Delfos e incluso de la región circundante, y los poetas cómicos de época clásica, sacándole punta al tema, representaban a los delfios viviendo de los peregrinos (26). Y los mismos habitantes de Delfos se daban cuenta de que la economía de la ciudad dependía del movimiento del santuario; hay indicios claros de su convencimiento de que la fortuna del templo y la prosperidad de la ciudad-estado venían a ser una misma cosa. Tan ello es así, que desde el poder público, digamos civil, se fomentaba la afluencia de peregrinos al santuario mediante una actividad de propaganda con no otra cosa que el aspecto financiero como móvil. Esto, que acerca el fenómeno de Delfos al de un turismo actual potenciado por la política de los estados, se podría decir también de otros santuarios famosos (27). Lo sabemos, por ejemplo, del santuario de Apolo en Delos, isla que casualmente estaba - que está, naturalmente - cerca del actual centro turístico de la isla de Mícono. Esta propaganda, aparte de atraer, intentaba aumentar la prodigalidad, el gasto generoso de los fieles, buscando no otra cosa que las ventajas económicas que las poblaciones residentes en las regiones con santuario sacaban de la afluencia de visitantes y del hecho mismo de las ofrendas.

Y hay otra cosa que querría decir, antes de terminar la breve referencia al fenómeno peregrino en Grecia. No se piense que el camino de Santiago tenga la exclusiva como fermento para las artes plásticas en lo tocante a desarrollo general y a la expansión de modelos. Las "panegirias" de Grecia, que eran al mismo tiempo que religiosas, reuniones políticas, culturales, deportivas, e inevitablemente feria de mercancías, representaron mucho de cara a un florecimiento de la actividad artística en todas sus manifestaciones (28).

Era frecuente en la época romana el viaje a Grecia, dada la fascinación que lo griego producía en los itálicos y occidentales en general. Y ese viaje se convertía en peregrinación cuando la ocasión era una fiesta y el lugar de atracción, el destino, un santuario. Atenas, que recibía muchos viajeros romanos, conocía una afluencia excepcional en ocasión de sus diversas celebraciones religiosas, algunas mencionadas anteriormente, y en especial con motivo de los misterios de Eleusis, que mantenían todo su esplendor (29) y que geográficamente no estaban lejos de la gran ciudad griega del Atica; estaban, precisando, en territorio ateniense. Financieramente mermada la ciudad durante la época romana, los ingresos de tales viajeros debían de ser básicos para la vida económica ateniense (30). Si se considera el esplendor de la Atenas de siglos pasados y los restos materiales todavía existentes en tiempos

(26) Marasco: I viaggi..., pág. 134.

(27) Marasco: I viaggi..., págs. 125 y ss.

(28) Marasco: I viaggi..., pág. 136.

(29) Mylonas: Eleusis..., pág. 155 y ss.

(30) Marasco: I viaggi..., pág. 82-83. 
romanos, no es abusivo suponer que los viajeros de primordial motivación religiosa se comportarían por las calles de la ciudad y entre sus monumentos como simples visitantes curiosos. Por ambas cosas sería posible establecer paralelo entre aquello y lo que es nuestro turismo actual. Resulta fácil, pues, comprender de lo dicho el interés que Atenas ponía en revitalizar los santuarios y fiestas de su territorio, en suscitar entre los extranjeros preocupación por su gloria pasada, reproduciendo especialmente sobre ese elemento de propaganda que eran las monedas (lo que ahora se hace con los sellos de correos) las fiestas, los templos, los monumentos en general y las viejas y gloriosas tradiciones.

Para el mundo romano propio el fenómeno es bastante más complicado. Hay santuarios oraculares de tipo y tradición griegos; por ejemplo el famosísimo de la Sibila de Cumas. Hay santuarios y lugares sagrados de antiquísima raigambre indígena prerromana, muy variable según las zonas (céltica, germánica, mediterránea). Está también la religiosidad oficial, en parte de origen itálico, en parte importada, y siempre con un notable ropaje de helenismo. Están las religiones orientales, asiáticas o egipcias, que se expanden por todo el mediterráneo hasta occidente. Está el culto oficial a los emperadores... El mundo de lo religioso se hace menos definido por más vario (31). Es conocido también aquí el fenómeno de la peregrinación; no sólo porque se importa de Oriente, se importa de Grecia, o lo conocen los celtas y en la Península Ibérica turdetanos, lusitanos e iberos, pongo por caso, sino porque no se puede negar que los pueblos itálicos conocieran el rito de acercamiento, que es - ya lo dije- consubstancial con la religión de santuario.

$\mathrm{Y}$ ahora el cristianismo antiguo. Por la tradición judaica, por la pagana, por el mismo sentimiento de piedad que establece unas referencias a lugares concretos relacionados con Jesús de Nazaret, con sus discípulos y con los mártires, el cristianismo no podía verse libre de no hacer suya la práctica peregrinatoria (32); práctica que gana fuerza en el siglo IV hasta constituirse en una de las devociones características (33) y que antes de la Edad Media tiene dos polos fundamentales de atracción, que son los Santos Lugares primero y Roma después, así como otros muchos secundarios: las numerosas tumbas de mártires y santos, dispersas por oriente y occidente (34). En la llamada Tierra Santa, en Palestina, básicamente Jerusalén, aunque ahora y para los cristianos por razones muy diferentes a las que movían al peregrino judío. Interesaban los lugares testigos de la vida y la muerte del Cristo. El Sepulcro, sobre todo (35). Como señaló hace años un medievalista francés, por

(31) Véase Dumézil, G.: La religión romaine archaïque, París, 1966; Ferguson, J.: The Religions of the Roman Empire, Londres, 1970; Blázquez, J. M.: Imagen y mito. Estudios sobre religiones mediterráneas e ibéricas, Madrid, 1977 y Liebetschuetz, J. H. N. G.: Continuity and Change in Roman Religion, Oxford, 1979.

(32) En general, Simon, M.: "Les pèlerinages dans l'antiquité chrétienne", Les pèlerinanges de l'antiquité biblique et classique à l'Occident médiéval, París, 1973, págs. 97 y ss.

(33) Marrou, H. I.: "Desde el Concilio de Nicea hasta la muerte de San Gregorio Magno", Nueva historia de la Iglesia, I, Madrid, 1964, pág. 355.

(34) Sobre las peregrinaciones en la Galia, Hispania, Italia, Roma aparte, y Norte de Africa, ChéliniBranthomme: Les chemins de Dieu..., págs. 86 y ss., y sobre las de la región oriental, págs. 64 y ss.

(35) Chélini-Branthomme: Les chemins de Dieu..., págs. 57 y ss.

(36) Labande, E. R.: "Recherches sur les pèlerins dans l'Europe dex XIe siècles", Cahiers de Civilisation Médiévale, I, 1958, pág. 159. 
paradoja, la tumba más deseada de la cristiandad, la de Jerusalén, estaba vacía, si bien era precisamente ese vacío lo que fundamentaba la fe del viajero (36).

Un cierto hipercriticismo de años atrás llevó a negar la posibilidad misma de una memoria fidedigna que transmitiera la ubicación e identificación de los lugares santos cristianos. Es decir, creían en estos círculos de crítica radical que se había perdido el recuerdo de los diferentes lugares sagrados del cristianismo, sea el Sepulcro, sea el Calvario, sea el Cenáculo, sea el Pretorio. Se afirmaba que la comunidad cristiana primitiva, emigrada de Jerusalén en el año 66, poco antes de la crisis que acabaría provocando la ruina de la ciudad, no regresó y no se reconstituyó grupo cristiano significativo y organizado hasta los días de Constantino, el emperador del edicto de tolerancia que dio fin a las persecuciones anticristianas. Según esta hipótesis, la falta de continuidad cristiana en Jerusalén y la transformación urbanística operada en la ciudad para dotarla de aspecto romano, hizo que se perdiera toda traza de los recuerdos topográficos e incluso de los propios monumentos relacionados con la vida privada y pública y el proceso y muerte de Jesús, o de algunos apóstoles y eclesiásticos de primera hora. Consecuentemente, los santuarios surgidos en época constantiniana serían - siempre en esta hipótesis - construcciones sin vinculación real a los auténticos lugares santos e incluso intencionados fraudes.

Hoy no se puede defender esto. La tumba de Jesús, por ejemplo, fue venerada por la comunidad primitiva y lo siguió siendo tras la guerra judaica, porque muchos cristianos, regresados a Jerusalén, todavía recordaban el emplazamiento. Luego, con las reformas urbanísticas del siglo II, el lugar quedó inaccesible y disimulado, pero perfectamente situado por los cristianos de la época. La información fue pasando de boca en boca y esta tradición sin solución de continuidad permitió que el sepulcro fuera fácilmente reencontrado en época de Constantino, cuando la actividad piadosa en Tierra Santa de Elena, la madre del emperador (37). Esto es lo probable; esto es lo que realmente ocurrió. Porque tenemos un testigo contemporáneo de Constantino, Eusebio de Cesarea, autor de una biografía del emperador, que lo confirma. Cuando Macario, el obispo de Jerusalén, pidió autorización al soberano, en ocasión del concilio de Nicea de 325, para hacer desaparecer cuanto en tiempos de Adriano se había construido sobre los lugares de la muerte, entierro y resurrección de Cristo, sabía muy bien dónde estaban dichos lugares. Macario fue sobre seguro. El obispo obtuvo ese permiso con toda facilidad, porque el propio Constantino había dado un decreto exigiendo a los paganos la restitución de las iglesias cristianas confiscadas por ellos y los sitios consagrados por la sepultura de los mártires; tanto más la del mártir por excelencia. Apenas llegado de Nicea, Macario, con la ayuda de las autoridades de la ciudad y bajo los altos auspicios de Elena, hizo demoler cuanto cubría los lugares santos y apareció el sepulcro sin dificultad. La memoria del sitio preciso se había conservado por tradición (38).

(37) de Sion, M. A.: La forteresse Antonia à Jérusalem et la question du Prétoire, Jerusalén, 1955, págs. 251 y ss.

(38) Parrot, A.: El Gólgota y el Santo Sepulcro, Barcelona, 1963, págs. 35 y ss. y Coüasnon, Ch.: The Church of the Holy Sepulchre in Jerusalem, Oxford-Londres, 1974, págs. 12-14. 
Al menos desde este momento, el trasiego de piadosos viajeros por Jerusalén fue constante. Tan frecuente viene a ser el viaje, que se publican guías y relatos con la finalidad de ayudar al peregrino durante el camino y luego en los propios santos lugares. Algunos de estos lugares se conservan. El más antiguo es el «Itinerario desde Burdeos a Jerusalén", redactado por un peregrino de la Galia anónimo por el año 333, y es una indicación de los caminos con su exacto metraje, por lenguas entre Burdeos y Tolosa y por millas desde Tolosa hasta Jerusalén. Este itinerario supone que la peregrinación a Jerusalén tenía ya detrás una cierta historia de desarrollo organizado (39). Posterior, pero de más interés, es el «Itinerario de Egeria», una monja hispánica, concretamente galaica. Es la descripción del viaje realizado por la autora desde Constantinopla a Jerusalén entre 383 y 385 (40). Un ilustre peregrino del siglo IV, a finales, es San Jerónimo, de quien sabemos que siguió prácticamente el mismo camino de Egeria y que luego se quedó en Belén para hacer vida cenobítica junto a la cueva de la Natividad (41).

El otro destino destacable de las peregrinaciones cristianas premedievales fue Roma. Fundamentalmente por las tumbas de los mártires, Pedro y Pablo entre ellos (42). Con posterioridad, es el carisma de algunos papas lo que actúa como elemento de atracción. También los viajeros a Roma necesitaban sus guías, como los de Jerusalén. El peregrino de la antigüedad, que se movía por rutas religiosas de mucho aflujo y por ciudades complicadas, precisaba de las atenciones que el viajero de cualquier tiempo y circunstancia exige, pero de manera particular estos manuales de uso que recogían la experiencia de viajeros anteriores. Sin estos auxiliares los peregrinos a Roma se habrían perdido entre tanta ruina, tanto santuario, tanta tradición y tanta historia (43). Conocemos también algunos de estos textos, redacciones del siglo VI en adelante sobre modelos anteriores, que, siguiendo las vías romanas, van marcando itinerarios, indicando monumentos, señalando catacumbas y tumbas de mártires y brindando explicaciones y aclaraciones de interés (44). Se evitaba al viajero con estos instrumentos la frustracción de descubrir al regreso que había perdido ocasión de visitar lugares fundamentales, y se le hacía el viaje en todo punto más fácil y satisfactorio. Lo importante era informar al peregrino sobre los santuarios martiriales, incluso cuando Roma, en los umbrales de la Edad Media, se convierte en la ciudad de los papas. Si el obispo Tajón de Zaragoza va a Roma en el siglo VII no es ya tanto atraído por los sepulcros de los mártires cuanto por la gran figura intelectual que había sido el papa Gregorio Magno (45). Pero los sepulcros martiriales siguen interesando al piadoso romero de la época y de después.

(39) Baus-H, K.-Ewing, G.: "Desde Nicea a Caldedonia", Manual de Historia de la Iglesia, II, Barcelona, 1980, pág. 447.

(40) Véase texto y estudio en Arce, A.: Itinerario de la Virgen Egeria, Madrid, 1980.

(41) Hunt, E. D.: Holy Land Pilgrimage in the Later Roman Empire, AD 312-460, Oxford, 1982, págs. 171 y ss.

(42) Chélini-Branthomme: Les chemins de Dieu..., págs. 81 y ss.

(43) Homo, L.: Rome médiévale, 476-1420. Histoire, civilisation, vestiges, París, 1956, pág. 195.

(44) Breve introducción y textos en Kirschbaum E.-Junyent, E.-Vives, J.: La tumba de San Pedro y las catacumbas romanas, Madrid, 1954, págs. 571 y ss.

(45) García Iglesias, L.: Zaragoza, ciudad visigoda, Zaragoza, 1979, pág. 69. 
Dos grandes religiones asiáticas antiguas conocen también la peregrinación como manifestación de piedad: el budismo y el mahometanismo. Antes de su muerte, según parece, Buda impuso la peregrinación a cuatro lugares testigos de significativos acontecimientos de su vida, desde su nacimiento hasta donde reposarían sus restos (46). Y en cuanto al islamismo, es bien conocida la peregrinación obligatoria de la Meca, con sus implicaciones religiosas, sociológicas y folclóricas (47); realidad en la que no insisto, porque, al sugir en la frontera entre la Antigüedad y el Medievo, queda fuera del período de mi especialidad y también de los límites dados a esta exposición.

Y hemos llegado al final de nuestro objeto de consideración. Pienso que a través de este repaso hemos podido asomarnos a las manifestaciones más importantes del fenómeno peregrino en el mundo antiguo. Pero, sobre todo, ha sido posible ver hasta qué punto el hecho de un viaje por motivos religiosos, el hecho de un viaje en general, tiene unas constantes intemporales, porque muchas de las implicaciones del viaje de hoy existían ya en el de hace tres mil, dos mil, mil quinientos años. Idénticas circunstancias tienden a producir idénticos efectos. En nuestro caso - la identidad, tantos siglos al medio, no existe-, parecidas circunstancias, parecidos efectos. ¿'Turismo peregrino? ¿Turismo en el mundo antiguo? La palabra no existía; puede que el concepto tampoco, al menos de forma precisa; pero el hecho, indudablemente sí. El viaje de fieles a los santuarios de la antigüedad nos ha permitido verlo.

(46) Raphaël: "Le pèlerinage...", pág. 12.

(47) Fahd, T.: "Le pèlerinage à la Mekke", Les pèlerinages de l'antiquité biblique et classique à l'Occident médiéval, París, 1973, págs. 65 y ss. 